\title{
Flexure behaviour of strengthened steel poles
}

\author{
M. Khedr ${ }^{1}$, T. Romeh ${ }^{2}$ \& A. Seleemah ${ }^{3}$ \\ ${ }^{1}$ Department of Civil Engineering, Benha University, Egypt \\ ${ }^{2}$ Alcatel-Lucent, Cairo, Egypt \\ ${ }^{3}$ Structural Engineering Department, Tanat University, Egypt
}

\begin{abstract}
Steel poles are widely used in several applications such as telecommunication, transmission and distribution, street lighting, and highway signs to name a few. It is not uncommon for a pole owner to request the addition of new equipment, attachments, etc. which can render the existing pole unsafe. If it is possible to strengthen the pole to accommodate the new suggested loads, a question needs to be asked, how? Traditionally, these types of structures are strengthened through welding steel plates to their shaft. However, this method is usually expensive, requires heavy lifting equipment and in site weld with an end product that lost its originally aesthetic look.

The current study suggests an alternative method for strengthening such structures using Glass Fibre Reinforced Polymers (GFRP) which is inexpensive, locally available, durable, with high strength/weight ratio and easily manipulated material. The main objective of this study is to investigate the flexural behaviour of the strengthened steel poles.

An experimental program is developed and tests are conducted on eight octagonal poles with two flat-width to thickness ratios and different strengthening configurations. The specimens are then loaded till failure through the application of single tip load. Results from strengthened poles tests showed an increase in the failure load between 26 to $36 \%$ depending on the strengthening configuration used.
\end{abstract}

Keywords: steel poles, local buckling, strengthening, GFRP.

\section{Introduction}

During the past two decades, the telecommunication industry has experienced significant growth in the wireless sector. The introduction of cellular phones and 
then the increased demand on their use required upgrading the existing cellular networks by adding or replacing existing antennas. As the need to install additional cellular equipment grows, existing supporting towers and poles are frequently found to be structurally inadequate and need to be strengthened. Traditionally, telecommunication steel poles are strengthened through welding steel plates to their shaft. However, this method is usually expensive, requires heavy lifting equipment and in-site weld with an end product that lost its originally aesthetic look. It is therefore necessary to develop a cost effective, durable strengthening system that significantly increases the strength and stiffness of poles without much impact on its appearance.

Fibre Reinforced Polymer sheets (FRP) have become an attractive alternative solution for strengthening steel members instead of the traditional strengthening techniques. Several researchers studied the problem of strengthening deficient flexural steel members using FRP. The majority of those researchers focused on using Carbon Fibre Reinforced Polymers (CFRP) in the strengthening of different structural steel shapes [1-4].

A recent study conducted at North Carolina State University suggested a strengthening technique for steel monopoles using high-modulus CFRP. The technique made use of the strength and stiffness qualities of CFRP to achieve an improvement in the load caring capacity of the monopoles. Transverse highmodulus CFRP sheets were used to delay the start of local buckling. This study showed that a significant improvement can be achieved in flexural yield and ultimate strength as well as stiffness can be obtained while the steel pole remains within elastic limits [5].

Using GFRP have not received as much attention due to its lower strength when compared to CFRP, however its use has proven to be beneficial in some cases as presented in the work done by El Damatty et al. (2005). In this study composite concrete-steel bridge girders were strengthened using GFRP with tensile strength of $207 \mathrm{MPa}$ and a modulus of elasticity of $17 \mathrm{GPa}$. It was concluded that a $25 \%$ increase in truckload can be achieved using the described system without any reported premature failure in the concrete slab, GFRP or adhesive [6].

When compared to CFRP, GFRP is found to be inexpensive and doesn't suffer from galvanic reaction with base steel which is a concern in CFRP and steel systems. GFRP has many other advantages such as its availability in the Egyptian market, low weight, economical usage and durability.

In this paper the results of an experimental investigation on the flexural improvement of GFRP strengthened steel poles are presented. The experimental program includes testing of eight octagonal steel poles with two flat-width to wall-thickness ratios. These ratios were chosen to fall within the two limits presented in the EIA/TIA-222- Rev. F and TIA-222-Rev. G [7] and [8]. Different GFRP strengthening configurations were considered in the experimental investigation. Steel and GFRP mechanical properties are kept constant for all specimens. All specimens are loaded till failure through the application of single concentrated load acting at the pole tip. 


\section{Experimental investigation}

\subsection{Specimens details and fabrication}

Tested steel poles were fabricated using grade S235 $3 \mathrm{~mm}$ thick steel sheets. Steel traps were formed into two identical half shells using press brakes measuring $1200 \mathrm{~mm}$ in length. The two halves were then welded to form a 185 $\mathrm{mm}$ and $230 \mathrm{~mm}$ flat to flat octagonal cross section denoted $\mathrm{C} 1$ and $\mathrm{C} 2$ respectively. $60 \%$ partial-penetration seem-weld was used along the length of the specimens except along the lower $150 \mathrm{~mm}$ near the base plate where full penetration weld was used.

Pole shaft was then welded to the S235 $16 \mathrm{~mm}$ thick steel base plate. Connection between steel shaft and base plate was achieved through the insertion of the shaft into the base plate and welding all around inner and outer fillet welds.

The formed poles were then attached to their concrete foundation blocks via the use of 8-22 $\mathrm{mm}$ in diameter anchor bolts.

Base plate thickness, anchor bolts diameter, anchor bolts length and concrete block dimensions as well as mechanical properties were all chosen to ensure that failure will occur in the pole shafts. Figure 1 shows general layout and dimensions of the tested specimens.

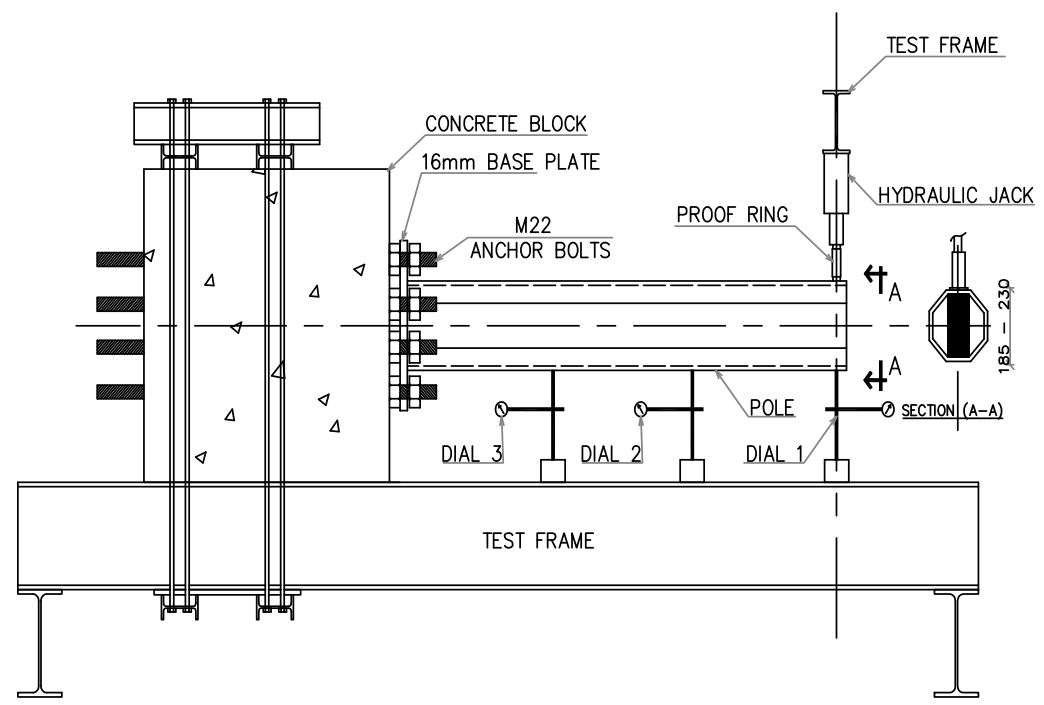

Figure 1: Specimen general dimensions and test setup.

Mechanical anchorage of the GFRP sheets in the form of square end plats was provided, when needed, and installed directly under the upper nuts. These plates are made of S235 steel and a thickness of $5 \mathrm{~mm}$. 


\subsection{Strengthening configurations}

Poles were strengthened using wet lay-up process of the bidirectional GFRP sheets orienting the fibres in both the longitudinal and transverse directions. Wet lay-up process enabled forming the GFRP sheets around the steel shaft to conform well to its octagonal cross sectional shape. Surface preparation was carried out prior to the strengthening process using sand blasting of the entire shaft as well as base plate. Strengthening was then applied using several configurations keeping in mind the shape of the bending moment due to the cantilever loading condition. The thickness of the applied GFRP sheets was the same from all layers. GFRP sheets were wrapped around the shaft cross-section in two halves with $50 \mathrm{~mm}$ overlap at mid-depth of the poles. Development length was provided by continuing the fibres past shaft base then bending the fibres on top of the base plate. Mechanical anchorage, when implemented, was provided through the use of $5 \mathrm{~mm}$ thick square steel plates placed between the anchor nuts and GFRP sheets.

Four different strengthening configurations were used, as shown in Figure 2, and were later denoted the subscripts 1 through 4 as follows:

1. Wrapping four layers of bidirectional GFRP sheets along the shaft in 2 halves with $50 \mathrm{~mm}$ overlap, each of the four layers has different length.

2. Same as 1 above but with the use of mechanical anchorage.

3. Wrapping four layers of bidirectional GFRP sheets along the shaft in 2 halves with $50 \mathrm{~mm}$ overlap with all four layers having the same length and mechanically anchored to the base plate.

4. Same as 3 above but using 6 layers of GFRP sheets instead.

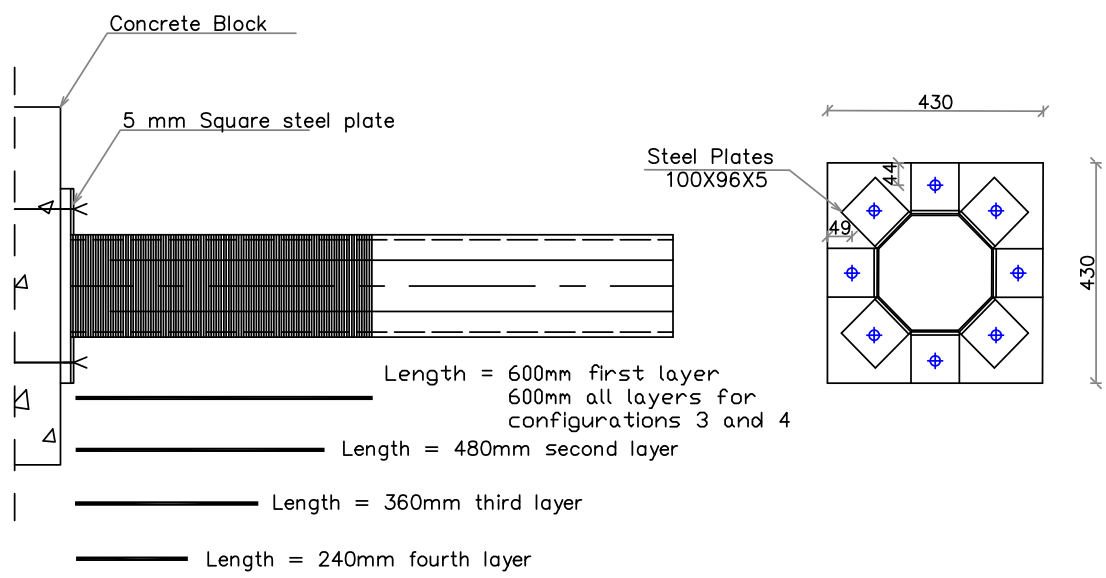

Figure 2: $\quad$ Strengthening configurations. 


\subsection{Test setup, specimens instrumentation and testing procedure}

A schematic view of the test setup is shown in Figure 1. The specimens were tested through the application of a single concentrated load at the tip point of the shaft, $1200 \mathrm{~mm}$ from base plate using a hydraulic jack. Load measurements were done using calibrated proofing ring that was placed under the hydraulic jack.

Vertical displacements were measured using displacement transducers located at the tip, middle and third points of the pole (Dials numbers 1, 2 and 3).

Strain gauges were placed on the shaft at one-third of its length measured from the base plate. Two Pairs of strain gauges were attached to each specimen, one pair on the tension side and the other on the compression side directly on top of the steel shaft underneath the GFRP layer as well as above the outermost GFRP layer.

Load was applied in increments of $2.50 \mathrm{kN}$ each. For each load step the load value, displacements, and strains were all read and recorded. Test continued till failure of the specimen was witnessed.

\section{Materials properties}

Tensile coupons were taken from all components of the pole specimens, namely shaft, base plate and anchor bolts. Tensile tests were then performed in a $1000 \mathrm{kN}$ capacity universal testing machine with controlled displacement with a rate of $0.05 \mathrm{~cm} / \mathrm{min}$. Table 1 lists the yield stress and tensile strength of the tested coupons.

Table 1: $\quad$ Material properties of the steel elements.

\begin{tabular}{|c|c|c|}
\hline Coupon taken from & $\begin{array}{c}\text { Yield stress, } \mathrm{F}_{\mathrm{y}}, \\
\mathrm{MPa}\end{array}$ & $\begin{array}{c}\text { Tensile strength, } \\
\mathrm{F}_{\mathrm{u}}, \mathrm{MPa}\end{array}$ \\
\hline Shaft & 350 & 418 \\
\hline Base plate & 350 & 418 \\
\hline Anchor bolts & 780 & 985 \\
\hline
\end{tabular}

Glass fibre used in the strengthening process is GFRP 800 having fibre density of $2.60 \mathrm{gm} / \mathrm{cm} 3$ and a thickness of $0.308 \mathrm{~mm}$. The manufacturer provided mechanical data sheet listed the modulus of elasticity as $73 \mathrm{GPa}$, tensile strength as $3400 \mathrm{MPa}$ and maximum elongation of $4.5 \%$. The GFRP 800 mechanical data were not independently verified.

BASF MBRACE ${ }^{\mathrm{TM}}$ epoxy primer was used, the properties of which are available in the manufacturer website [9].

\section{Test results and discussions}

\subsection{Description of failure modes}

Several failure modes were observed during testing the specimens that can be summarized below: 
- For the Control specimens $\mathrm{C} 1$ and $\mathrm{C} 2$, local buckling failure of the shaft near the base plate was observed as shown in Figure 3.

- For first strengthening configuration, specimens C11 and C21, the failure modes changed to either:

a. Debonding failure in the adhesive layer.

b. Local buckling failure associated with GFRP debonding, as shown in Figure 4.

- After including the mechanical anchorage system and for specimens C12 and C22 rupture failure mode took place in the GFRP layers near the point of maximum bending stresses, see Figure 5.

- Increasing the number of GFRP layers to 4 layers in C13 and C23 resulted in a change in the failure mode to flexure failure. With further increase of the number of layers to 6 layers of GFRP, C14 and C24, the failure load increased further with no change in the failure mode itself.

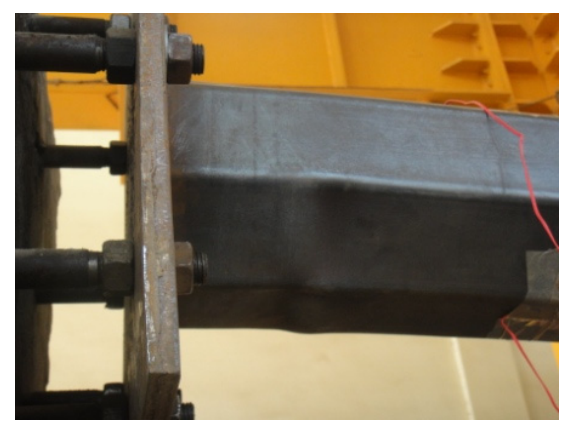

Figure 3: $\quad$ Local buckling failure in $\mathrm{C} 11$ and C21.

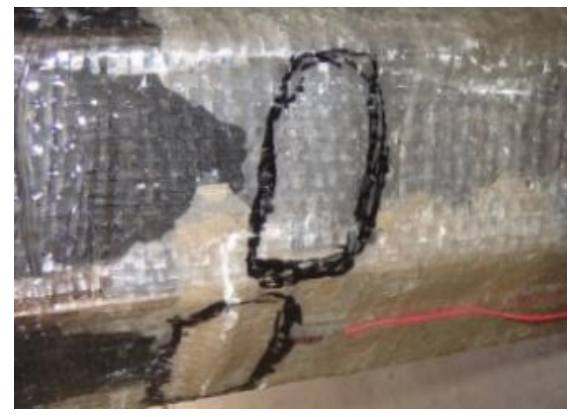

Figure 4: Debonding of the GFRP layers with local buckling failure. 


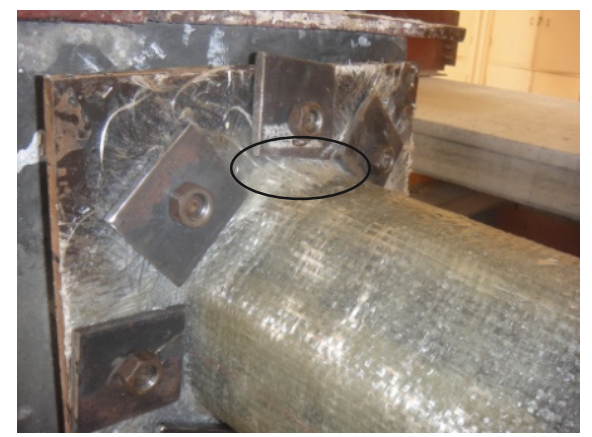

Figure 5: GFRP rupture failure at the top anchorage plate location.

\subsection{Results}

The tip displacements of the 10 tested pole specimens for each load step were measured then plotted against the applied load as shown in Figures 6 and 7 for group $\mathrm{C} 1$ and $\mathrm{C} 2$ respectively.

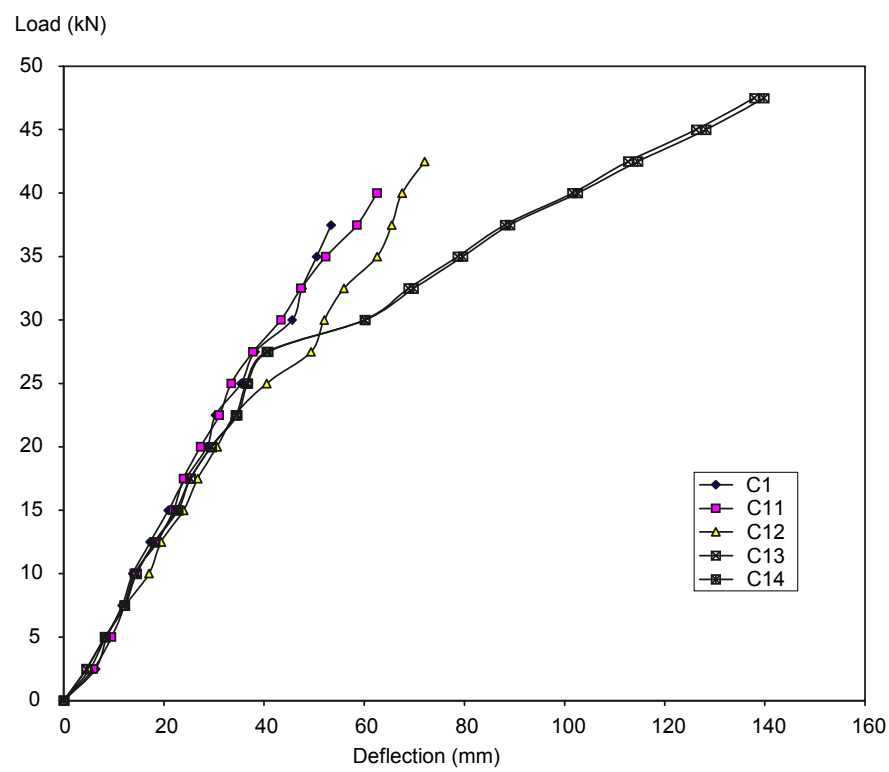

Figure 6: $\quad$ Load displacement at $1200 \mathrm{~mm}$ for group C1 specimens. 


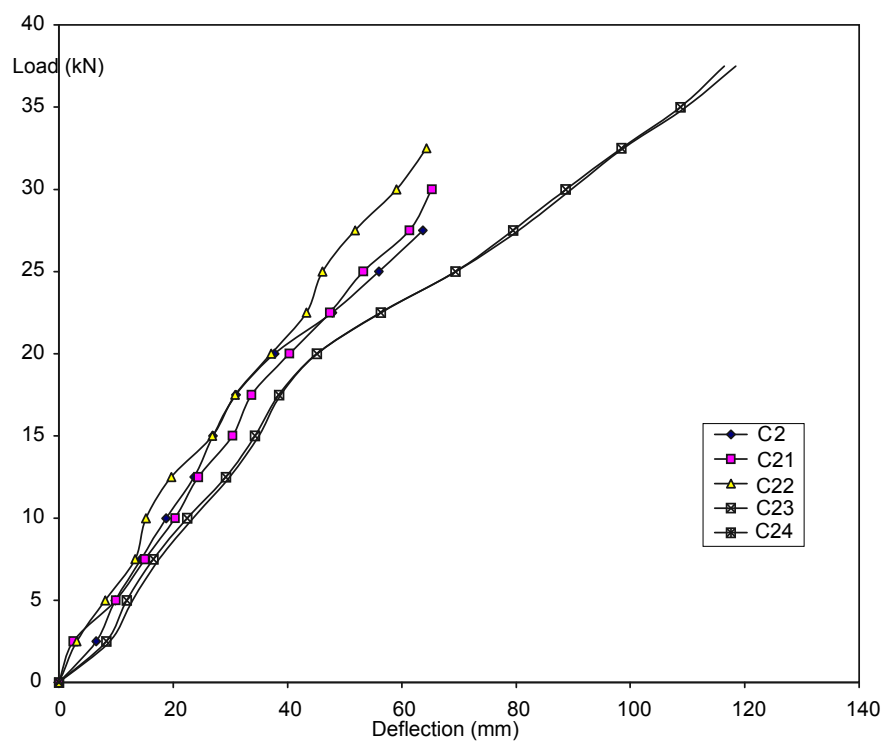

Figure 7: $\quad$ Load displacement at $1200 \mathrm{~mm}$ for group C2 specimens.

Studying these figures it is noticed that for both tested groups the loaddeflection curves of the strengthened specimens are very close to that of the control specimen especially in the elastic zone. This means that there was no significant increase in the specimens stiffness associated with the suggested GFRP strengthening configurations.

It is also noticed that for specimens C1, C11 and C12 and C2, C21 and C22 the load deflection curves maintained a linear trend till the failure of the 6 specimens and that these specimens did not exhibit any nonlinear behaviour before failure. For $\mathrm{C} 13$ and $\mathrm{C} 14$ and $\mathrm{C} 23$ and $\mathrm{C} 24$, non-linear behaviour is apparent in the load-deflection curves.

From the load displacement graphs it can also be seen that, although the slope of the strengthened specimens did not change dramatically when compared to the control ones an increase in the load at failure of about $26 \%$ and $36 \%$ was achieved for specimens $\mathrm{C} 1$ and $\mathrm{C} 2$ respectively.

The strain gauges readings are shown in Figures 8 and 9. From these figures, two observations need to be mentioned. The first is on the compression branches of the curves, where the occurrence of local buckling is apparent for specimens $\mathrm{C} 1$ and $\mathrm{C} 12$ and $\mathrm{C} 2$ and $\mathrm{C} 22$. It can also be seen that strengthening configurations 2, 3 and 4 prevented the occurrence of local buckling. Looking at the tension branches of the two figures, it is also evident that the strain associated with the strengthening configurations 3 and 4 has exceeded the yield strain of the base metal. 


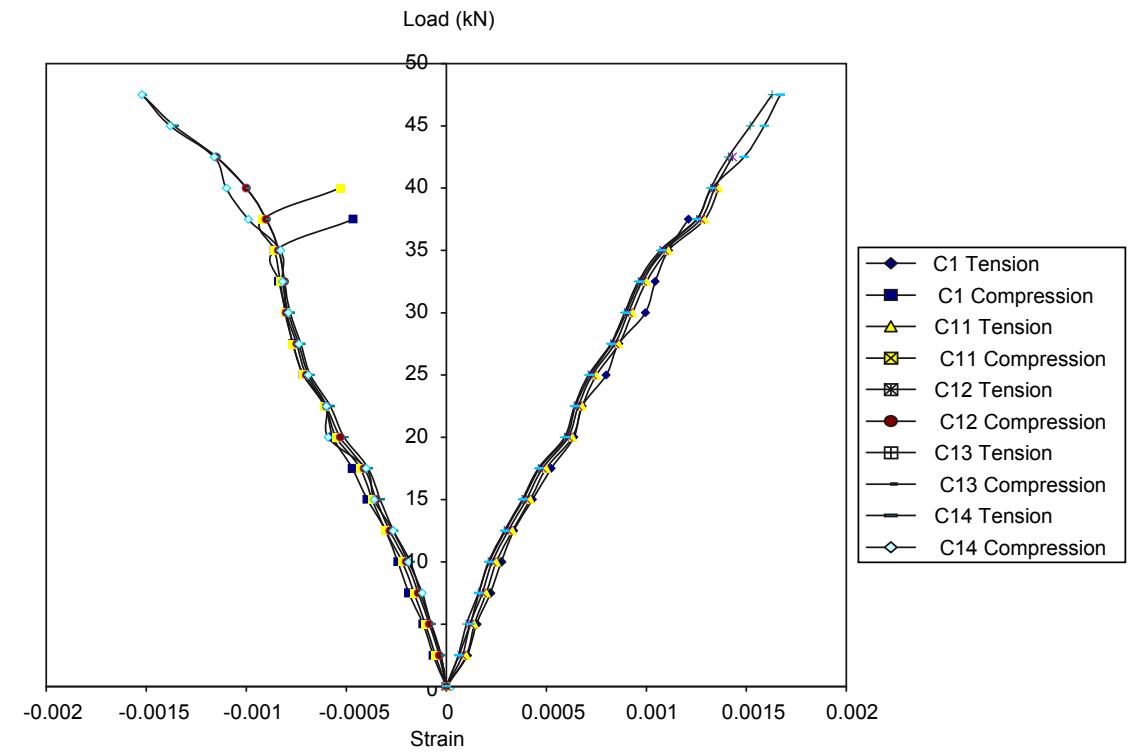

Figure 8: $\quad$ Load strain group C1 specimens.

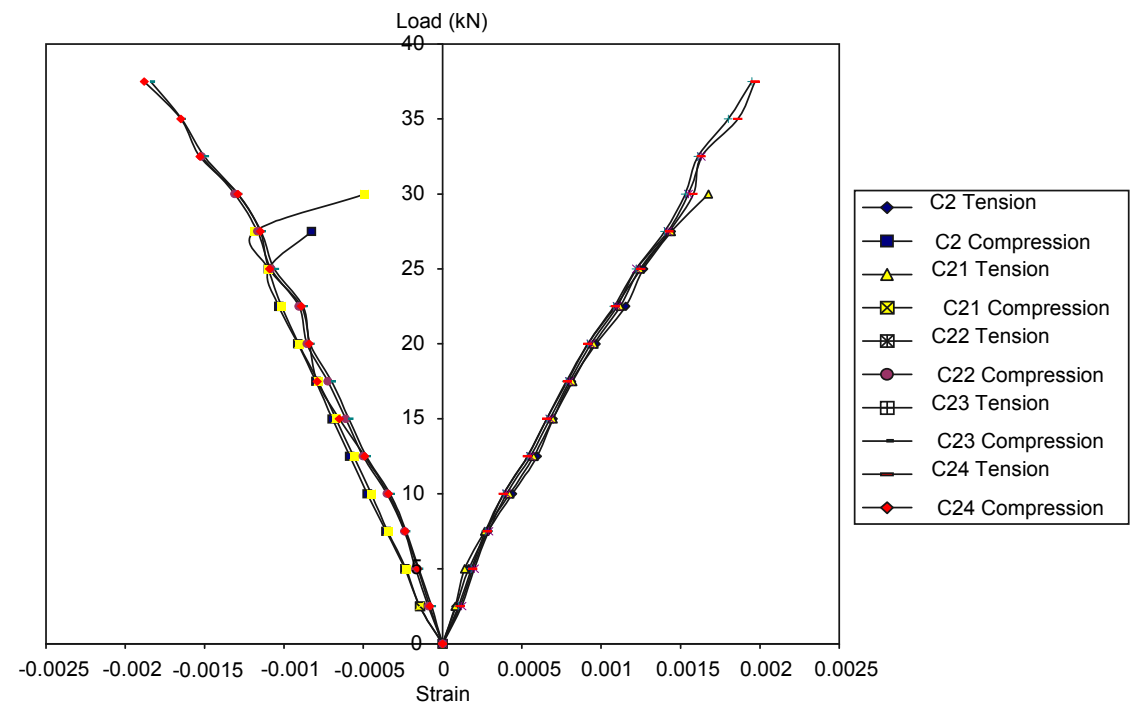

Figure 9: Load strain for group C2 specimens.

\section{Conclusions}

The current study has shown that high-modulus GFRP materials can be used to improve the flexural strength of steel poles by delaying the formation of local 
buckling in the compression zone. Similar to the findings of previous studies, the use of mechanical anchorage in the form steel plates attached to the anchor bolts has proven essential in preventing debonding of the glass fibre sheets. An up to $36 \%$ increase in the flexural strength of the strengthened steel poles has been achieved associated with one of the suggested strengthening configurations. This is attributed to the fact that GFRP has provided confinement to the specimens hence delayed the onset of local buckling. When strength rather than stiffness is the issue, high-modulus GFRP materials proved to be an effective and economical method of strengthening steel poles.

\section{References}

[1] Colombi, P. and Poggi, C., An experimental, analytical and numerical study of the static behavior of steel beams reinforced by pultruded CFRP strips. Composites: Part B, 37, pp. 64-73, 2006.

[2] Deng, J., Lee, M., and Moy, S., Stress analysis of steel beams reinforced with a bonded CFRP plate. Composite Structures, 65, pp. 205-215, 2004.

[3] Linghoff, D., Al-Emrani, M. and Kliger, R., Performance of steel beams strengthened with CFRP laminate - Part 1: laboratory tests. Composites: Part B, 41, pp. 509-515, 2010.

[4] Schnerch D, Dawood M, Rizkalla S, Sumner E. and Stanford K., Bond behavior of CFRP strengthened steel structures. Advances in Structural Engineering, 9(6), pp. 805-817, 2006.

[5] Lanier, B., Schnerch, D., and Rizkalla, S., Behavior of steel monopoles strengthened with high-modulus CFRP materials. Thin-Walled Structures, 47, pp. 1037-1047, 2009.

[6] El Damatty, A., Abushagur, M. and Youssef, M., Rehabilitation of Composite Steel Bridges Using GFRP Plates. Applied Composite Materials, 12, pp. 309-325, 2005.

[7] TIA-222-F, Structural standards for steel antenna towers and antenna supporting structures, Telecommunications Industry Association: Arlington, VA, June 1996.

[8] TLA-222-G, Structural standard for antenna supporting structures and antennas, Telecommunications Industry Association: Arlington, VA, August 2005.

[9] http://www.basf.com 